DOI 10.37882/2223-2974.2020.11-2.06

\title{
РОЛЬ ЦИФРОВОГО МАРКЕТИНГА В КОММЕРЧЕСКОЙ ДЕЯТЕЛЬНОСТИ КОМПАНИЙ
}

\section{THE ROLE OF DIGITAL MARKETING IN THE BUSINESS OF COMPANIES}

A. Kozoriz

Summary: This article explores the role of digital marketing in the business of the company. The author outlined the relevance and practical significance of the topic of the study. The place and peculiarities of transformation of the concept of digital marketing in the development of the private sector in the era of digitalization are considered. The role and characterization of tasks that perform chat bots as a key tool of digital (personalized) marketing has been studied.

Keywords: digital marketing, personalized marketing, artificial intelligence, chat bots, omnichannel approach, client-oriented strategy.

\section{Введение}

$\mathrm{C}$ овременный период характеризуется разворотом очередной волны трансформации моделей деятельности в бизнес- и социальной среде, что, фактически, является результатом появления и развития так называемых «сквозных» технологий, т.е. цифровых технологий нового поколения, обладающих масштабностью и особой глубиной влияния. Речь идет об искусственном интеллекте, робототехнике, Интернете вещей, виртуальной и дополненной реальности (AR, VR), технологиях беспроводной связи [11, с. 4]. Их проникновение во все сферы человеческой жизнедеятельности изменяет и способы коммерческого взаимодействия, т.е. коммуникации потребителя и производителя определенных благ.

Неоспорим тот факт, что клиент, потенциальный или реальный, в определенной степени связан с брендом (брендами) широким спектром цифровых каналов, среди которых мессенджеры, мобильные приложения, сайты, социальные сети, «виртуальные помощники» и пр. Однако, важно принимать во внимание тот факт, что в центре этой цифровой экосистемы, digital-паутины, находится пользователь, который желает взаимодействовать с компанией по доступным именно ему каналам, в удобное для него время, для того чтобы комфортно совершать свой клиентский путь (customer journey). Как результат, в целях привлечения потенциальных и удержания реальных клиентов, компании вынуждены пред-
Козориз Андрей Викторович

аспирант, Российский экономический университет

им. Г.В. Плеханова

alx2018@ya.ru

Аннотация: Статья посвящена изучению роли цифрового маркетинга в коммерческой деятельности компании. Автором обозначена актуальность и практическая значимость темы исследования. Рассмотрено место и особенности трансформации концепции цифрового маркетинга в развитии частного сектора в эпоху цифровизации. Изучена роль и дана характеристика задачам, которые исполняют чат-боты как ключевой инструмент цифрового (персонифицированного) маркетинга.

Ключевые слова: цифровой маркетинг, персонализированный маркетинг, искусственный интеллект, чат-боты, омниканальный подход, клиенториентированная стратегия. принимать соответствующие технологические решения для переформулирования еще вчера действенной и приносящей стабильный поток потребителей, cmpameгии клиенториентирования.

Разработка клиентоориентированной стратегии, В первую очередь, подразумевает выявление наиболее перспективных групп клиентов и разработку соответствующих программ и бизнес-процессов, ориентированных на повышение их лояльности. Исходя из уровня значимости (статуса) клиента для компании, распределяются уровни персонализации его обслуживания. Достижению данной цели в последние годы способствуют инструментарий цифрового (digital) маркетинга, порождающий совершенно новую концепцию клиенториентированного маркетинга. Так, если в классическом клиенториентированном маркетинге ключевыми показателями являются объем продаж (прибыльность товара), доля на рынке, стоимость и доходность покупателя, в рамках современного клиенториентированного маркетинга к этому перечню добавляется длительность коммуникации с потребителем и качество клиентского сервиса.

Целью данной статьи является изучение современных тенденций в применении инструментов цифрового маркетинга для перестройки стратегии клиенториентирования компаний в соответствии с реалиями современности, где диджитализация является бизнес-приоритетом. 


\section{Роль и особенности трансформашии коншепции шифрового маркетинга в развитии частного сектора в эпоху шифровизашии}

Бесспорен тот факт, что в мире становятся все более активными процессы, которые требуют новых подходов к трансформации взглядов на управление маркетингом. Так, развитие информационного общества, экономики знаний, процессов глобализации вызывают необходимость использования исключительно нового формата маркетинга - цифрового маркетинга, парадигма которого должна постоянно эволюционировать, создавая условия для успешного развития и конкурентного позиционирования субъектов частного сектора с учетом реалий современности. Одновременно с этим, следует принимать во внимание, что цифровизация маркетинговой деятельности - это, как отмечает Т.В. Мизина, отнюдь не просто интеграция в соответствующие бизнес-процессы информационно-коммуникационных или «сквозных» технологий, это «процесс перехода всего предприятия к новым способам мышления и работы при помощи различных digital-технологий» [6], для достижения ключевой цели - создания оптимального механизма взаимодействия с клиентом и обеспечения качественного клиентского сервиса.

Данный тезис подтверждается бренд-трендом, актуальным и в сегменте b2c, и сегменте b2b, заключающимся в такой категории, как «гиперперсонализация». К примеру, если в начале 2000-х гг. коммуникативный контент лишь визуально адаптировался к различным устройствам, то сегодня, на рубеже второго и третьего десятилетия XXI в., он успешно анализирует, синтезирует и систематизирует информацию о пользователе, мгновенно и на постоянной основе предоставляя ему все необходимое «здесь и сейчас». Аналитики PwC coвершенно верно отмечают, что современный клиент это не просто самое сильное звено в цепи мировой экономики; продукты диджитализации позволили им занять такое положение, в котором они могут буквально требовать индивидуального подхода, независимо от того, какой канал взаимодействия избран, какой подход для обеспечения потребителю ощущения социальной ответственности применен, и какая социальная сеть (цифровой инструмент, канал) связывает обе стороны [2]. Кроме того, формулируемый на современном этапе массив digital-маркетинговых коммуникаций позволяет разрабатывать персонализационные механизмы сразу в нескольких направления: по предпочтениям, по именам, по геологии, по гендерному признаку, по семейному положению и пр. Таким образом, основываясь на данных о клиенте и его действиях, компания может обеспечить все необходимые условия для прохождения им своего customer journey. Исходя из этого, можно заключить, что бренды стараются максимально уменьшить дистанцию между ними и клиентами, создавая для последних омни- канальные сервисы и интегрированные digital-каналы. Такая формация цифрового маркетинга в научном мире носит название персонифицированного (персонализированного). Как отмечает И.Ю. Окольнишникова, маркетинг отношений и персонифицированный маркетинг различны лишь доминирующими каналами коммуникации: «маркетинг отношений использует личный канал коммуникации, а персонифицированный маркетинг цифровой канал» [7, с. 135].

Персонализированный маркетинг - это форма взаимодействия клиента и бренда, основанная на интересах, потребностях и целях первого. С помощью персонализированного digital-маркетинга это взаимодействие укрепляется, т.к. усиливается доверие к бренду, повышается потребительская лояльность; у предприятия, в свою очередь, растет конверсия, увеличиваются продажи, возникает эффект отдачи от клиента. С позиции маркетологов, именно персонифицированный подход на сегодняшний день признается наиболее эффективным в контексте маркетингового продвижения бренда и совершенствования коммерческой деятельности предприятий. Данный тезис подтверждают данные различных аналитических агентств, например, эксперты Dimension Data отмечают, что компании, персонализирующие подход к клиентам, увеличивают продажи в среднем на 19\%. Так, 73\% потребителей в США предпочитают бренды, которые используют их личные данные, чтобы обеспечить более релевантный потребительский опыт [8]. Следовательно, если предприятие будет знать, кто его клиенты, то бренд будет иметь возможность: первое - разрабатывать уникальный контент, направленный именно на ключевые сегменты потребителей, второе - создать индивидуализированные рекламные материалы, проводить рекламные и event-мероприятия, и, третье - формировать персонализированные обращения, причем вне зависимости от формата (лендинги, информационные и пр.), они будут иметь социально-экономический эффект.

Говоря только о бизнес-деятельности компании, можно акцентировать на ряде следующих достоинств персонализированного маркетинга - кастомизации в целях выделения среди конкурентов, персонификации в целях поддержки коммуникации с клиентами и индивидуализированного лендинга для получения места в определенной бизнес-нише (см. подобнее рис. 1).

Сказанное позволяет заключить, что маркетинг в классической своей вариации проходит своеобразную эволюцию; изначально его задачами были нормирование объема продаж и преумножение прибыли и товарооборота посредством привлечения новых и удержания действующих клиентов. Теперь же, будучи персонифицированным, маркетинг нацелен на клиента как субъекта цифровой среды, а ключевой задачей является - максимальная пролонгация b2c-контакта (b2b-контакта). 


\begin{tabular}{|c|c|}
\hline $\begin{array}{c}\text { Кастомпзация } \\
\text { для вьцеленшя } \\
\text { среди } \\
\text { конкурентов }\end{array}$ & $\begin{array}{l}\text { Предприятия, осуществляющие свою деятельность в одной отрасли, } \\
\text { отличаются друг от друга не только количеством сотрудников или } \\
\text { фирменньм стилем. Однако, часто отличия не столь заметны, так как часто не } \\
\text { имеют значения для потребителя. Данная проблема может быть решена } \\
\text { посредством персонифицированной стратегии и рекламы. Индивидуальньй } \\
\text { подход к клиентам вьделяет бренд среди конкурентов, что, безусловно, } \\
\text { можно считать конкурентньм преимуществом, даже в условиях применения } \\
\text { идентичньх маркетинговьх инструментов сконкурентами }\end{array}$ \\
\hline $\begin{array}{c}\text { Персоншфикация } \\
\text { для поддержанця } \\
\text { компунпкацпи с } \\
\text { клшентамп }\end{array}$ & $\begin{array}{l}\text { В рамках персонифицированного маркетинга целесообразно предусматривать } \\
\text { или «живой» чат на сайте или лендинге, или чат-бота с искусственньм } \\
\text { интеллектом, т.е. развивающегося (в т. ч. умеющего взаимодействовать с } \\
\text { клиентом на естественном дпя него язьке). Вспльвающее окно с реальньм } \\
\text { или виртуальньм помощником позволит всегда быть на связи с } \\
\text { потенциальньми покупателями. Данньй инструмент не только усиливает } \\
\text { эффективность взаимодействия с клиентами, но и экономит временнье } \\
\text { ресурсы, разгружая при этом саll-центр }\end{array}$ \\
\hline $\begin{array}{c}\text { Персонпфикация } \\
\text { леңдпнпа для } \\
\text { полученшя нпшши } \\
\text { в бизнесе }\end{array}$ & $\begin{array}{l}\text { Это одна из кпючевьх задач, которую, многие ор ганизации, оставпяют без } \\
\text { допжного внимания. На лендинге, или продающей странице, не должно быть } \\
\text { каких-либо сведений о компании, иньпи словами, лишней информаци, } \\
\text { способной отвлечь клиента от шош-эффекта. Лендинг - это полноценная } \\
\text { витрина, у которой проработан и контент, и пизайн, спедовательно, с первого } \\
\text { посещения посадочной страницы у клиента должно сложиться попожительное } \\
\text { впечатление от бренда и начать формирование лояльности кнему }\end{array}$ \\
\hline
\end{tabular}

Рис. 1. Достоинства персонализированного маркетинга для брендов (составлено автором)

\section{Чат-боты как кАючевой инструмент шифрового (персонифичированного) маркетинга}

Современные мировые тенденции в области ведение конкурентоспособного бизнеса все больше отходят от ориентации на текущие показатели продаж и стремятся развивать долгосрочные взаимоотношения со всеми внешними субъектами экосистемы частного сектора [9, с. 3]. Интеграция клиенториентированного подхода в систему управления организацией предполагает модернизацию ее элементов с учетом более плотного контакта с потребителями, в целях приведения деятельности компании в соответствие с требованиями рынка.

В последние годы все больше внимания уделяется клиенториентированному подходу со стороны экспертного сообщества, как российского, так и зарубежного. Впервые об ориентации на клиента заговорили в начале 80-х гг. XX в. Р. Сакс и Б.А. Вейтз. По их мнению, клиенториентированность представляет собой «помощь клиентам в совершении покупок, которые удовлетворяют их потребности» [16]. Уже в начале нового тысячелетия Дж. Нарвером и С. Слатером было дано более расширенное определение: «клиенториентированность - это понимание целевых покупателей, удовлетворение их потребностей, полное понимание их цепочки создания ценности и ее развития в будущем, понимание нужд не только собственных клиентов, но и всех членов распределительного канала» [15]. С нашей точки зрения, именно такой подход сегодня актуален в формулирование клиентоориентированной стратегии. Приведем еще трактовку, автором которой является Т. Хенинг-Трау; он определили клиенториентированность как «ориентацию сервисного персонала на клиента, обеспечиваемую техническими и социальными навыками, мотивацией и полномочиями принятия решений» [12]. Интерес здесь представляет акцент маркетолога на персонале, который обеспечивает взаимодействие с клиентом. В наш век - век цифровизации человеческий ресурс заменяется на искусственный интеллект.

Действительно, на современном этапе категорию «клиенториентированность» принято считать неотъемлемой частью феномена цифровизации. Например, авторы презентации крупнейшей в России энергетической компании ПАО «Россети» «Концепция цифровизации сетей» [5] определяют цифровизацию, как бизнес-категорию, следующим образом: «это инструмент достижения качественно нового уровня в области надежности, доступности, эффективности и клиенториентированноcmu». В этой достаточно емкой трактовке отражена вся суть digital-трансформации современного частного сектора. По справедливому замечанию известного эксперта в области поведенческого маркетинга А. Даллакяна, современный клиент - это «не столько источник дохода компании, сколько непосредственная часть (субъект) ее экономической системы» [4], а значит основной задачей предприятия является выстраивание партнерских отношений между брендом и потребителем. Следовательно, вектор стратегии клиенториентирования должен быть направлен на формулирование и развитие таких отношений.

Следует согласиться с позицией О.В. Иванченко и Е.А. Семерниковой о том, что эволюция маркетинга партнерских отношений является «одним из ключевых факторов повышения конкурентоспособности и адаптации бизнеса к динамичным реалиям рыночной среды» лишь 


\begin{tabular}{|c|c|}
\hline 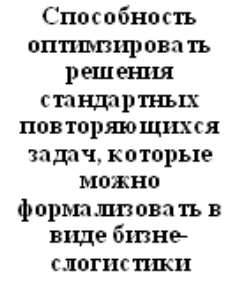 & $\begin{array}{l}\text { Это касается как коммуникации бизнеса с внешними субьектами экосистемы так и } \\
\text { внутренними. К таким задачам относится, например, проверка соответствия счетов от } \\
\text { контрагентов принятым в компании нормам. Чат-бот может сам проверить доку мент, } \\
\text { найти ошибки, написать контрагенту и попросить его исправить счет и сообщить } \\
\text { менеджеру, когда документ нужного формата будет готов. Аналогинно чат-бот может } \\
\text { обрабатьвать заявления на отпуск, собирать у сотрудников отчеты об отработанньг } \\
\text { часах и сводить их в таблицу. Очевидньй эффект для компании подобньг случаях - это } \\
\text { сокращение расходов и экономия времени сотрудников. Неочевидным эффектом можно } \\
\text { считать системное мотивирование сотрудников организации. }\end{array}$ \\
\hline $\begin{array}{c}\text { Обеспеченпе } \\
\text { обра тной связи с } \\
\text { пользова телямп по } \\
\text { приншпу « } 24 / 7 » \text { в } \\
\text { лю бьх каналах }\end{array}$ & $\begin{array}{l}\text { Клиентский сервис во всех его форматах - от технической поддержки до проверки } \\
\text { статуса доставки заказа курьером - становится решающим фактором успешности } \\
\text { любого бизнеса в сфере b2с. Уникальность функционала чат-ботов заключается в том, } \\
\text { что значительное количество пользовательских вопросов повторяются и являются в той } \\
\text { или иной степени стандартньпи, и с практически всегда могут справиться боты. Речь } \\
\text { идет как о чате, так и голосовьг беседах - современнье боты умеют понимать и } \\
\text { синтезировать речь. Эффективность, в данном случае, преимуцественно } \\
\text { экономическая, однако, использование чат-ботов в поддержке обладает и другим } \\
\text { преимуществом - автоматические собеседники могут проводить анализ статистики } \\
\text { разговоров и находить зоны в системах компании, которые чаще всего создают } \\
\text { проблемьддляпользователей. }\end{array}$ \\
\hline
\end{tabular}

Мессенджерами пользуются, по данным телекоммуникационньх компаний, до $70 \%$ взросльгх россиян [1]. В отличие от приложений или сайтов, в мессенджерах общение Продажи и осуществляется посредством диалога, и клиента не требуется изучать новьй интерфейс. $\begin{array}{lll}\text { маркетинг в } & \text { и для представителей } \mathrm{Y} \text { и } \mathrm{Z} \text { поколения, мессенджерь, являются наиболее часто }\end{array}$ мессенджерах вьпустили или планируют вьпустят решения, позволяющие, не вьгодя из чата производить безопасную оплату товаров и услуг. Соответственно, мессенджерь становятся новым цифровым каналом продаж и маркетинга, инструментом для этого канала собственно, которьдм и являются чат-боты Следовательно, посредством чатботов маркетинг переходит от сегментации к гиперперсонализации.

\begin{tabular}{|c|c|}
\hline $\begin{array}{c}\text { Иск.по ченте } \\
\text { человеческого } \\
\text { фактора из } \\
\text { процесса } \\
\text { компунпкацпи }\end{array}$ & $\begin{array}{l}\text { Данная фунция чат-ботов наиболее актуална для HR. Они берут на себя роль } \\
\text { анонимного и безличного собеседника, в целях исключения из процесса лишних } \\
\text { эмоции. Это касается таких задач, как сбор обратной связи, принуждение сотрудников к } \\
\text { своевременной сдаче отчетов, ежегодная оценка персонала и пр. В качестве примера } \\
\text { можно привести индийский Аmber, созданньй для компаний, руководители которьгх } \\
\text { хотят бьпь в курсе проблем сотрудников. Атbеr задает вопрось, а затем создает отчеты } \\
\text { для СЕО, рассказьвая об общих трендах в компании и обращая внимание на зоны риска } \\
\text { [14]. }\end{array}$ \\
\hline
\end{tabular}

Рис. 2. «Омниканальные» задачи чат-ботов (составлено автором)

в условиях его ориентации на «наиболее полное удовлетворение запросов потребителей без ограничения временного горизонта сотрудничества» [3, с. 1]. Действительно, как мы уже писали выше, приоритетной бизнесзадачей сегодня является пролонгация контакта бренда с клиентов, что с помощью цифровых технологий, таких как искусственный интеллект, коммуникативный контент, мобильный и голосовой поиск, социальные сети, инфлюенсы и нарративная реклама, защита персональных данных, чат-боты и пр., становится более реальным.

В рамках настоящей статьи считаем целесообразным обратиться к технологиям чат-ботов и искусственного интеллекта, так как эти бизнес-новации, по сути, единственные на конкретный момент времени цифровые продукты, которые способны к объединению всех, или большинства цифровых каналов коммуникации бренда и клиента. Здесь мы говорим, собственно, об эффекте омниканальности, т.е. единой системе, информационной архитектуре, которая воедино связывает разного рода коммуникативные каналы. В.В. Панюкова отмечает, что реализация омниканального подхода в маркетинге в потенциале позволяет, во-первых, расширить долю рынка посредством расширения спектра маркетинговых каналов и масштаба охвата целевой аудитории; во-вторых, интегрировать персонифицированные программы лояльности с помощью единой базы данных о клиенте; в-третьих, повысить рыночную стоимость деловой репутации компании посредством усиления фактора узнаваемости бренда на рынке среди потенциальных и реальных потребителей; в-четвертых, значительно преумножить объем товарооборота компании, а значит и оптимизировать прибыльность.

Чат-боты, как омниканальный инструмент, становятся все популярнее; например, по данным Intercom, в 2019 г. они сэкономили отделам техподдержки и продаж в среднем по 300 тыс. долл., при этом: 74\% пользователей положительно отнеслись к встрече с роботом на сайте [17]. В большинстве своем, ключевое достоинство чат-ботов, которое фактически и привлекает, или по меньшей мере не отталкивает клиентов - это многозадачность «виртуальных помощников» (рис. 2).

Делая акцент на концепте омниканальности как таковом, следует обратить внимание на то, то чат-боты - это программы продукты, которые способны к интеграции в различные информационные системы внутри бизнессреды. Они с легкостью интегрируются и взаимодействуют с любыми информационными системами предпри- 
ятия (бухгалтерией, аналитикой, комплексами CRM, BPM и пр.). Соответственно, не только в контексте маркетинга, но и в контексте управления компанией бренда чатботы являются эффективным инструментом. Так, персоналу уже не нужно учиться работать в интеркомной программе, созданной специально под предприятие, равно как и тратить время на ввод данных. Бот вполне может справиться с задачей ассистента, например, он способен создавать отчеты, анализировать данные, заполнять формы, напоминать о выполнении тех или иных функций, отвечать на вопросы, задавать их сотрудникам вышестоящих или нижестоящих инстанций. Такими способностями чат-ботов могут пользоваться, к примеру, и специалисты в области отбора и найма персонала, не затрачивая время на систематизацию данных о кандидатах на определенную должность. В целом, следует говорить о том, что если бизнес-процессы компании сформулиро- ваны с задействованием информационных технологий (не только программ), то чат-боты могут в значительной степени их оптимизировать.

О перспективности чат-ботов как актуального омниканального коммуникатора прогнозы, например, консалтинговой компании ОС\&С, эксперты которой отмечают, что к 2022 г. мировой объем покупок с помощью чат-ботов вырастет в двадцать раз и достигнет 40 млрд. долл. [10]. Однако, следует помнить, что, как уже говорилось выше, цифровая трансформация маркетинговых процессов - это именно направление мышления, т.к. неразумное внедрение цифровых технологий в бизнеспроцессы предприятия - это еще не цифровая трансформация. Компании должны поставить в императив задачу по интеграции омниканального подхода к самому маркетингу, и только после этого - адаптации маркетингового инструментария к новой стратегии персонификации.

\section{ЛИТЕРАТУРА}

1. ВымпелКом оценил популярность мессенджеров среди своих абонентов. - 06.05.2017 // PБK. - ULR: https://www.rbc.ru/technology_and_media/06/03/2 017/58b99c419a79473e6841bfbd (дата доступа 02.10.2020)

2. Глобальное исследование потребительского поведения 2019 // Официальный сайт PwC. - ULR: https://www.pwc.ru/ru/retail-consumer/publications/gcis2019-ru.pdf (дата доступа 02.10.2020)

3. Иванченко 0.В., Семерникова Е.А Концепция маркетинга партнерских отношений в деятельности предприятий малого бизнеса // Концепт. - 2015. №S24. $-7 \mathrm{C}$.

4. Кибер-Банкинг. Клиенториентированность в эпоху цифровизации: [Видео] Вебинар, - 11.07.2017 // 0фициальный сайт Paдио «M». - ULR: https://radio. mediametrics.ru/kiber-banking/51084/ (дата доступа 02.10.2019)

5. Концепция цифровизации сетей: [Презентация]. ПАО «Россети». - 05.03.2018 // Портал «Protariff». - ULR: http://protariff.ru/uploads/W6ZHUk0hY1xpVrW1. pdf (дата доступа 02.10.2019)

6. Мизина T.B. Digital Transformation: потребность или тренд? // Самоуправление. - 2019. - № 2 (115). - С. 404-406

7. Окольнишникова И.Ю. Анализ подходов к оценке эффективности маркетинговых коммуникаций // Вестник ЮУрГу. Серия: Экономика и менеджмент. 2011. - №28 (245). - С. 134-142.

8. Персонализированный маркетинг: что, когда, зачем. - 06.11.2018 // «Medium». - ULR: https://medium.com/инсайты-и-стратегии-для-женщин/персонализированный -маркетинг-что-когда-зачем-ба19d61ab126 (дата доступа 03.09.2020)

9. Рожков А.Г. Формирование и развитие отношений клиентоориентированной компании: дисс. ... к.э.н.: 08.00.05 / Рожков Александр Геннадьевич; [Место защиты: Нац. исслед. ун-т "Высш. шк. экономики"]. - М., 2012. - 181 с.

10. Фуколова Ю. Трудно быть ботом. - 14.11.2018 // HARVARD BUSINESS REVIEW POCCИЯ. - ULR: https://hbr-russia.ru/innovatsii/tekhnologii/778769 (дата доступа 03.10.2020)

11. Что такое цифровая экономика? Тренды, компетенции, измерение Ч-80 [Текст]: докл. к XX Апр. междунар. науч. конф. по проблемам развития экономики и общества, Москва, 9-12 апр. 2019 г. / Г.И. Абдрахманова, К.О. Вишневский, Л.М. Гохберг и др. ; науч. ред. Л.М. Гохберг ; Нац. исслед. ун-т «Высшая школа экономики». — М.: Изд. дом Высшей школы экономики, 2019. - 82 с.

12. Hennig-Thurau T. Customer orientation of service employees: Its impact on customer satisfaction, commitment, and retention // International Journal of Service Industry Management. - 2004. - Vol. 15. - №5. - P..460-478

13. Making progress in health, together // Официальный сайт IBM - ULR: https://www.ibm.com/watson-health (дата доступа 06.10.2020)

14. Meet Amber. She's an engagement bot who chats with employees and helps CHROs find those who are... // Портал «InFeedo». - ULR: https://infeedo.com/ (дата доступа 09.10.2020)

15. Narver J.C., Slater S.F. and MacLachlan D.L. Responsive and Proactive Market Orientation and New-Product Success // Journal of Product Innovation Management. - 204. - № 21. - P. 334-347.

16. Saxe R. and Weitz B.A. The SOCO scale: a measure of the customer orientation of salespeople // Journal of Marketing Research. - 1982. - Vol. 19. - pp. 343-51.

17. $80 \%$ of businesses want chatbots by 2020 - 14.12.2016 // International. - ULR: https://www.businessinsider.de/80-of-businesses-want-chatbots-by-20202016-12?r=US\&IR=T (дата доступа: 09.10.2020)

( ) Козориз Андрей Викторович (alx2018@уа.ru). 